\title{
Cable Thermal Risk Estimation for Overplanted Wind Farms
}

\author{
M. Angelica Hernandez Colin, Member, IEEE, and James A. Pilgrim, Senior Member, IEEE,
}

\begin{abstract}
This paper presents a methodology for the forward estimation of thermal risk in offshore wind farm cables under scenarios where the farm is overplanted for economic purposes. A dynamic thermal rating assessment of the cable is proposed to estimate the thermal effects of probable load current scenarios considering actual temperatures. Calculated future temperatures are used to estimate the probability of the cable being overheated. Due to the ability of the method to estimate forward thermal risk, unnecessary power curtailment can be reduced while avoiding thermal damage to the cable. Simulated results of online thermal risk estimation and curtailment show additional power delivery of $7.26 \%, 9.16 \%$ and $9.67 \%$ per year for a $6 \% 9.9 \%$ and $13.7 \%$ wind farm overplanting respectively. The additional power is calculated compared to the annual power delivered (Wh/year) with the use of the traditional continuous rating limits for the case studied.
\end{abstract}

Index Terms-Underwater cable, probabilistic estimation, thermal risk, wind energy, wind farms, optimisation, overplanting, power transmission.

\section{INTRODUCTION}

Offshore cable sizes are often based on continuous rating calculations (IEC60287) [1] which estimate the maximum ampacity of the cable. The main limitation for rating calculations is the maximum temperature of the insulation material and the varying environmental thermal parameters along the cable route which are a key medium for heat dissipation [2]. Although, other countries have established thermal restrictions such as the $2 \mathrm{~K}$ criteria evaluated for a point in the seabed above the cable for ecological purposes [3], in most countries this criteria is not applied and ratings are based on conductor temperature limitations.

Wind farm export cables face intermittent power generation which can lead to low cable temperatures and under-utilisation of cable capacity. Given that export cables represent a significant percentage of the capital expenditure (CAPEX) of an offshore wind farm, optimisation of cable size is essential to reduce the levelised cost of energy (LCoE) [4]. Because of the low temperature profiles found in submarine export cables, a common practice in offshore wind farm projects is wind farm overplanting (WFO) and the consideration of load cycles at a design stage in order to optimise cable sizing/rating [3], [5], [6].

WFO aims to optimise transmission capacity by increasing the installed generation capacity over the continuous rating of

The authors are with the Tony Davies High Voltage Laboratory, University of Southampton, Southampton SO171BJ, UK (e-mail: mahc1n14@soton.ac.uk; jp2@ecs.soton.ac.uk).

Maria Angelica Hernandez Colin studies are sponsored by the Mexican Council of Science and Technology (CONACYT) and Mexico's Energy Secretariat (SENER) the cable. The extra installed capacity captures more energy at low wind speeds while power curtailment is applied when high speeds generate full power over long durations. Although loading the cable over the conservative continuous rating limits could introduce the possibility of exceeding the cable temperature limits, for projects in which it is necessary to reduce LCoE a balance between optimisation of cable utilisation and system margins can be achieved [4], [7].

Distributed temperature sensors (DTS) are used as a tool for cable and ambient temperature monitoring in order to optimise the cable system capacity [8]-[11]. Additionally, DTS can be used as a security measure to generate instantaneous alerts and avoid thermal damage in the cable. However, a methodology that considers the thermal dynamics of the cable and the future uncertainty in the wind power generation to estimate thermal risk hours in advance can help to avoid unnecessary power curtailment at times when the generated power is higher than the continuous rating, but the cable temperature is low.

Dynamic rating methodologies have been used successfully in conventional installations on land to increase the cable ampacity compared to static ratings [12]. They measure or estimate actual environmental conditions to calculate the cable temperature and assess permissible future loading i.e. [13][15]. However, real-time rating calculations do not consider uncertainty of power generation into the future, making them hard to apply to offshore wind power applications.

Numerous methodologies exist to perform forecasting and estimation of wind speed and power generation in wind farm installations, broadly divided in physical and statistical approaches. The former are based on weather models and meteorological stations to estimate wind speed given weather variables in the studied site [16], [17] while the latter make use of statistical modelling of weather variables using historical data [18]-[20]. Statistical approaches can be easily applied and can be accurate given that they are based on patterns found in historical data over specific periods of time. The most common methodologies include Moving Average (MA), Auto-Regressive Moving Average (ARMA), Auto-Regressive Integrating Moving Average (ARIMA) and Markov Chain (MC) models [21], [22].

When forecasting wind generation, the cubic relation between power and wind speed has been identified as the main source of errors, given that, a small wind prediction error generates a large power output error [22]. Additionally, meteorological models designed for prediction of weather onshore cannot be directly applied in offshore environments where the wind speed changes have a stronger impact on generation due to the flatness of the environment [21], [22]. 
A small number of works study how the fluctuating power generation is reflected in the thermal rating of the cable. For instance [5] studied the thermal effect of a cyclic load profile in offshore cables as a technique to optimise the sizing of cables while [23] studied the thermal behaviour of the aerial part of power cables in offshore wind sites considering stochastic wind power generation with the similar objective to optimise cable sizing. The results of these studies evidenced the capacity to reduce cable sizing for cable systems operated under highly variable loads. An example of industrial application considering a dynamic cable sizing/rating technique is described in [6] where a worst-case dynamic load profile is derived from historical data and used in the planning stage of the Horns Reef $3400 \mathrm{MW}$ offshore wind farm by the Danish TSO Energinet.dk allowing a $25 \%$ reduction in cable size.

This paper proposes a methodology for the forward estimation of thermal risk in offshore wind farm cables under wind farm overplanting. The dynamic algorithm calculates the real-time thermal rating of the cable while also estimating the thermal effects of sampled future load current scenarios considering its actual temperature. The calculated $6 \mathrm{~h}$ ahead cable temperatures are used to estimate the probability of the cable being overheated. The methodology does not attempt to forecast weather variables but estimates the likely load scenarios based on the direct relationship between historical data and the statistical analysis of the load current generation profile. Finally, the focus of the paper is towards the performance evaluation of the proposed methodology as a tool that could be used 1) in early stages of wind farm projects to test and evaluate possible increments in rating or reduction of cable sizing, or 2) as a tool for planned and controlled curtailment strategies. In the latter case reliable temperature monitoring technology in limiting spots along the line is a required factor as a protection mechanism against thermal damage in the cable.

\section{Proposed Methodology}

\section{A. Methodology Overview}

The proposed methodology is a non-parametric analysis of historical data based on Markov Chain (MC) models to predict probable load current states, from which a Monte Carlo Simulation (MCS) generates a series of likely load current scenarios that the cable could experience in the following hours. A finite difference model (FDM) is used to solve the thermoelectric equivalent network of the cable and calculate the temperature in real time, while a subroutine of the algorithm calculates the cable temperatures given the estimated load current scenarios and the actual cable temperatures. The resulting probability distribution of temperatures is analysed to estimate a likely risk of thermal overheating $6 \mathrm{~h}$ ahead.

\section{B. Markov Chain Models (MCM)}

Markov Chain models are used to model stochastic processes in order to generate probabilistic forecasts i.e. wind speed and wind power forecasts [20], [24]. They are based on the statistical analysis of data from the variable studied and the selection of a finite number of states thus they present nonrestrictive or parametric characteristics regarding the probability distribution function (PDF) of the data. The analysis of the historical data is used to build a Transition Probability Matrix (TPM) containing the probabilities of change, of the variable, from one state at time $t$ to another one at $t+1$.

Time series load current data sets are studied in this paper and the system states are defined based on the percentage of rated heat produced in the cable. MCM considering a different number of states $q=4(4 S), q=8(8 S)$ and, $q=17(17 S)$; with first (MC1) and third (MC3) order TPM were modelled and tested in order to select the most accurate for the purpose of thermal risk estimation in the offshore case scenario.

1) Defining system states: Given that the heat output in the cable is approximately proportional to the square of the load current, $50 \%$ of the maximum load current $I_{s}$ (calculated as in IEC60287) would generate $25 \%$ of heat output in the cable. This assumes negligible dielectric losses, while charging current must be considered carefully as discussed in section VI. The percentages of heat output selected to calculate load current limits according to the number of states are: $4 S=[15,50,75,100](\%), 8 S=[15,30,50,60,70,80,90,100]$ (\%), $17 S=[15,25,30,35,40,45,50,55,60,65,70,75,80,85$, $90,95,100](\%)$.

2) First Order MC-TPM: For the studied variable $I$ a discrete number of states $q$ is selected such that $Q=\{1,2, \ldots q\}$ are the system states, thus, the probability of transition from state $i$ to state $j$ is defined as

$$
p_{i j}=p\left\{I_{(t+1)}=q_{j} \mid I_{(t)}=q_{i}\right\}, \forall i, j \in\{1,2, \ldots, q\} .
$$

To capture seasonal behaviour, these transition probabilities are calculated based on the analysis of the historical data on a monthly basis (eq. from [20]) as

$$
p_{i j}=\frac{\text { historical transitions of } q_{i} \rightarrow q_{j}}{\text { historical transitions of } q_{i} \rightarrow Q},
$$

to form the elements of the TPM $\mathcal{P}_{m}$ such that

$$
\mathcal{P}_{m}=\left[\begin{array}{ccc}
p_{11} & \cdots & p_{1 q} \\
\vdots & \ddots & \vdots \\
p_{q 1} & \cdots & p_{q q}
\end{array}\right]
$$

where $m=\{1,2,3 \ldots 12\}$. Depending on the number of states in the system the size of $\mathcal{P}_{m}$ increases i.e. $q$ system states generates a $q$ by $q$ matrix.

The obtained one-step TPM can estimate the most probable state of the system at time $t+1$ considering the actual state at time $t$ while its successive powers i.e. $\mathcal{P}_{m}^{h}$, result in the calculation of the most probable state at time $t+h$.

3) Third Order MC-TPM: Additional to the testing of a greater number of system states, third order TPM were studied. Following the process for the calculation of the first-order MCTPM in (1) where the estimation of state $t+1$ depends only on the state at time $t$, in a 3rd order MC-TPM the transition probabilities $p_{i j}$ are calculated as

$$
\begin{aligned}
& p_{i j}=p\left\{I_{(t+1)}=q_{j} \mid I_{(t)}=q_{i}, I_{(t-1)}=q_{j}, I_{(t-2)}=q_{k}\right\} \\
& \forall i, j, k \in\{1,2, \ldots, q\} .
\end{aligned}
$$


Equation (4) implies that the probability of the load current state at time $t+1$ depends on the analysis of the states at $t$, $t-1$ and $t-2$.

The study of additional past data values i.e $t-3$, could improve the accuracy of the estimations however, the complexity of the TPM calculation will be increased which would require higher computational times and computer capabilities.

\section{Scenario Sampling}

The estimation of the most probable future state $q$ at time $t+h$ is followed by the random sampling of load current values from the PDF formed by the data in state $q$ for the month in which the estimation is performed. Matrix $X$ is built by $n$ series of $h$ load current values as

$$
X_{(n \times h)}=\left(\begin{array}{ccc}
x_{11} & \ldots & x_{1 h} \\
\vdots & \ddots & \vdots \\
x_{n 1} & \ldots & x_{n h}
\end{array}\right)
$$

where $n$ represents the number of iterations in the MCS and $h$ represents the number of steps ahead in the estimation.

\section{Submarine Cable Finite Difference Model (FDM)}

A FDM of the cable is used to calculate the cable temperature dynamically considering hourly load current updates in the model. The thermoelectric equivalent circuit of the submarine cable with a jacket around each core is based on the model proposed in [25].

The circuit differential equations for the calculation of temperatures at nodes of interest are obtained and approximated using the backward difference approach, defined as (from [26])

$$
\frac{d}{d t} \theta_{z}=\frac{\theta z(t)-\theta z(t-1)}{\Delta t} .
$$

The obtained system of linear equations $A \times u=B$ is solved for $u$ at each time step to obtain the temperatures at each node of the cable considering changes in load current data.

It is known that for the case of 3-core SL-type, armoured, submarine power cables the IEC60287 calculation of the armour losses $\lambda_{2}$ may produce overestimated values [9], [27] which leads to additional conservatism in the calculated ratings. The present paper is focused on the performance evaluation of the risk estimation methodology, for a given thermal model.

\section{E. Thermal Risk Estimation}

The main FDM described above $\left(f d m_{\text {main }}\right)$ is depicted inside the green rectangle in Fig. 1, it calculates the dynamic temperature of the cable at time $t$ while a subroutine of the same FDM $\left(f d m_{s u b}\right)$, depicted inside the red rectangle, evaluates the sampled load current scenarios in the system considering temperatures in the cable at time $t$ as initial conditions.

1) Forward Estimated Risk: A forward estimation of thermal risk $\mathcal{R}^{\prime}$ is calculated at each time step $t$ considering the probabilistic distribution of conductor temperature $\left(\operatorname{PDF}_{\mathcal{T}_{c}^{\prime}}(t)\right)$ obtained from $f d m_{s u b}$. The risk $\mathcal{R}^{\prime}(t)$ is calculated by

$$
\mathcal{R}^{\prime}(t)=\frac{\mathcal{T}_{c}^{\prime}(t+1, \ldots, t+h) \geq \mathcal{T}_{\text {limit }}}{h}
$$

where $\mathcal{T}_{c}^{\prime}(t+1, \ldots, t+h) \in \operatorname{PDF}_{\mathcal{T}_{c}^{\prime}}(t)$ represents the $h$ most probable conductor temperatures considering the central tendency values.

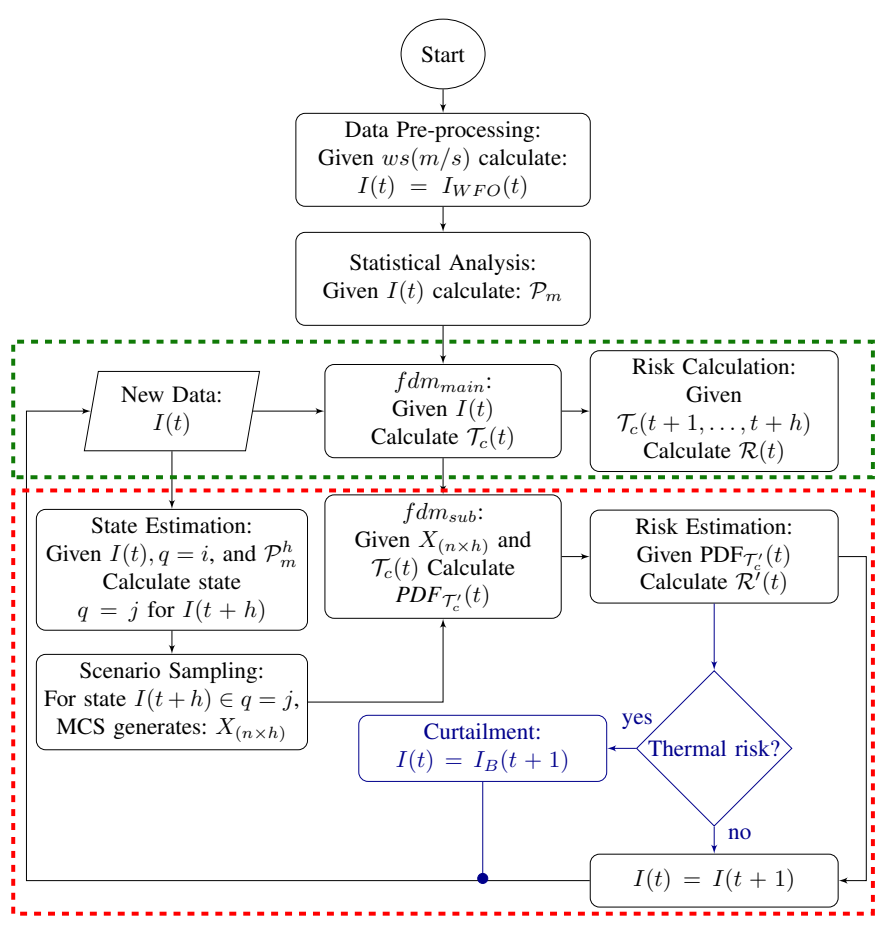

Fig. 1. Offline (black) and online (black+blue) methodology, flowchart.

2) Realistic Thermal Risk: The realistic thermal risk $\mathcal{R}$ is calculated considering the conductor temperatures calculated by $f d m_{\text {main }}$. Given that $\mathcal{R}^{\prime}(t)$ represents a likely thermal risk $h$ hours ahead, the conductor temperatures $\mathcal{T}_{c}$ from time $(t+1)$ to $(t+h)$ are used to estimate the thermal risk $\mathcal{R}(t)$ as

$$
\mathcal{R}(t)=\frac{\mathcal{T}_{c}(t+1, \ldots, t+h) \geq \mathcal{T}_{\text {limit }}}{h}
$$

which reflects the number of occasions on which the cable temperature exceeded $\mathcal{T}_{\text {limit }}=90^{\circ} C \cdot \mathcal{R}^{\prime}(t)$ and $\mathcal{R}(t)$ are given in a [0 to 1] range where $1=100 \%$ thermal risk $h$ hours ahead.

Additionally, to the estimated risk $\mathcal{R}^{\prime}(t)$ an interval of likely conductor temperatures is derived at each time step from $\operatorname{PDF}_{\mathcal{T}_{c}^{\prime}}(t)$. The central value of the interval, $\mathcal{T}_{c^{50}}^{\prime}(t)$, is represented by the 50th percentile which is the value below which the $50 \%$ of the observations in the sampled $\mathrm{PDF}_{\mathcal{T}_{c}^{\prime}}(t)$ fall. The minimum and maximum values of the interval are given by the $5 t h$ and $95 t h$ percentiles, $\mathcal{T}_{c^{5}}^{\prime}(t)$ and $\mathcal{T}_{c^{95}}^{\prime}(t)$ respectively.

\section{Definition OF CASE Study}

\section{A. Description of Cable System}

The export cable studied is a $132 \mathrm{kV} 3$-core XLPE insulated cable, $800 \mathrm{~mm}^{2}$ copper conductor, with a $\mathcal{T}_{\text {limit }}=90^{\circ} \mathrm{C}$. The underwater section of the cable is considered assuming normal installation conditions: $1000 \mathrm{~mm}$ burial depth; $15^{\circ} \mathrm{C}$ ambient temperature; and $0.7(K \mathrm{~m} / \mathrm{W})$ soil thermal resistivity. The length of the submarine section is assumed as $50 \mathrm{~km}$, a oneline diagram of the cable system is presented in Fig. 2.

The assumed environmental parameters and burial depth are kept constant for the section of the cable studied however, this can be easily modified to study a different section of the cable 
such as a limiting hot spot or multiple analysis of the cable at $k$ different sections considering different soil parameters i.e thermal conductivity, laying depth and ambient temperature.

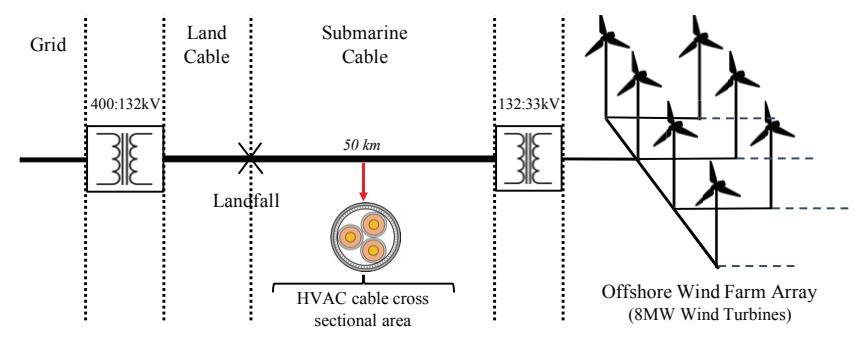

Fig. 2. One-line system diagram.

\section{B. Wind Speed Data and Generation Profiles}

The study analysed two data sets of hourly sampled wind speed data, extrapolated from $50 \mathrm{~m}$ to $110 \mathrm{~m}$ over sea level. Data set 1 (DS1) is dated from 01/01/1996 to $31 / 12 / 2015$ while data set 2 (DS2) is dated from 01/01/1979 to $19 / 02 / 2016$ these are representative of different offshore locations in the North Sea and have been obtained from MERRA analysis [28].

The time series wind speed data was converted to power output using the power curve model of an $8 M W$ wind turbine (Vestas 160-8). The output power is multiplied by the number of turbines in the wind farm conservatively assuming no wake losses. A reductive factor for wake losses could easily be added once details of wake losses for a particular site are known.

1) Base Case Wind Farm (BWF): The BWF is sized according to the continuous current of the cable, $I_{s}=923 \mathrm{~A}$ calculated as per $I E C 60287$ [1]. Given the selected wind turbine power curve the BWF size is defined considering the number of $8 M W$ wind turbines connected without exceeding the maximum continuous rating $I_{s}$. Thus the resulting output power of the BWF is $208 \mathrm{MW}$ per cable represented by $26 \times 8 \mathrm{MW}$ wind turbines, $I_{B_{\max }}=910 \mathrm{~A}$.

2) Wind Farm Overplanting Cases (WFO): The variable output power of wind farms ensure that the cable temperature limit is never reached or exceeded if it is sized by the static rating. Thus for the purpose of the proposed methodology, overplanting cases are defined by the addition of a greater number of wind turbines compared to the BWF. The three overplanting cases studied are: WFO1 $=106 \%$ represented by 28 turbines, $I_{\max }=980 A$; WFO2 $=109.9 \%$ represented by 29 turbines, $I_{\max }=1015 \mathrm{~A}$ and; WFO3 $=113.7 \%$ represented by 30 turbines, $I_{\max }=1050 \mathrm{~A}$.

A load cycle characterised by a 45 day period of $77 \%$ load followed by a 7 day full load period $(100 \%)$ as in [3] was tested for the case of WFO1 and the temperature profile obtained is shown in Fig. 3 along with the realistic temperature profile for the same case. The results showed that the use of generalised load cycles might not always be suitable for different wind farm locations. For instance, the use of the mentioned load cycle applied to DS1 would ensure no risk of thermal overheating for WFO1 while in reality the highly variable loads during winter are underestimated.

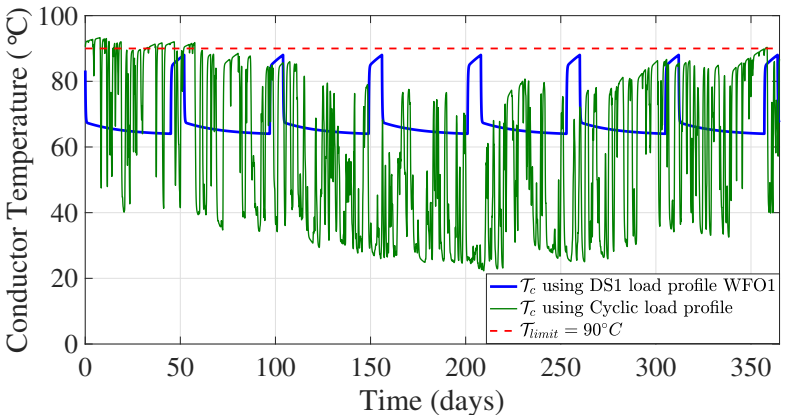

Fig. 3. Conductor temperature profile using cyclic load vs real load.

\section{Simulation and Evaluation Process}

The computational algorithm and the simulations described below were developed using MatLab software. The described MCM analysed the first 5 years of DS1 and DS2 to obtain the TPM's while year 2015 was used for testing. All the models were tested considering DS1 and a $6 \mathrm{~h}$ ahead estimation window while DS2 was used to demonstrate that the methodology can be applied to different offshore locations given its nonparametric nature.

Previous work considering longer estimation windows $(12 \mathrm{~h}$ and 24h) and the use of 10 and 19 years of historical data [29], led to the selection of the $6 \mathrm{~h}$ window as this time is enough for planning and performing curtailment in an offshore installation. Additionally, the use of 5 years of data for the statistical analysis was proved to be enough to perform accurate estimations.

\section{A. Offline Thermal Risk Estimation}

The offline simulation, shown in black in Fig. 1, consists of the calculation of hourly $6 \mathrm{~h}$ ahead thermal risk estimations and conductor temperatures for the given WFO case over the year of testing data.

The estimated variables $\mathcal{R}^{\prime}(t), \mathcal{T}_{c^{50}}^{\prime}(t), \mathcal{T}_{c^{5}}^{\prime}(t)$ and $\mathcal{T}_{c^{95}}^{\prime}(t)$ are stored at every time step while the corresponding $\mathcal{T}_{c}(t+6)$ and $\mathcal{R}(t)$ are calculated $6 \mathrm{~h}$ into the future. The variables are then used to calculate the accuracy of the methodology to estimate likely thermal risk ahead.

1) Accuracy of Risk Estimations: The accuracy of the method to calculate thermal risk $6 \mathrm{~h}$ ahead is first evaluated considering the classification presented in Table I comparing $\mathcal{R}(t)$ and $\mathcal{R}^{\prime}(t)$ calculated during one year. This approach reflects the actual success of the methodology in estimating a thermal risk $6 \mathrm{~h}$ ahead.

TABLE I

Classification of ESTIMATEd Risk

\begin{tabular}{|c|c|c|c|}
\hline & \multicolumn{2}{|c|}{$\mathcal{R}$} \\
\hline & & $\mathcal{R}>0$ & $\mathcal{R}=0$ \\
\hline \multirow{2}{*}{ ผ } & $\mathcal{R}^{\prime}>0$ & $\begin{array}{l}\text { True Positive } \\
\text { (TP) }\end{array}$ & $\begin{array}{l}\text { False Positive } \\
\text { (FP) }\end{array}$ \\
\hline & $\mathcal{R}^{\prime}=0$ & $\begin{array}{c}\text { False Negative } \\
\text { (FN) }\end{array}$ & $\begin{array}{c}\text { True Negative } \\
\text { (TN) }\end{array}$ \\
\hline
\end{tabular}


Additionally, the error between the estimated $\left(\mathcal{R}^{\prime}\right)$ and realistic $(\mathcal{R})$ thermal risk are evaluated considering the mean absolute error (MAE)

$$
M A E=\frac{1}{g} \sum_{t=1}^{g}\left|\mathcal{R}(t)-\mathcal{R}^{\prime}(t)\right|
$$

and root mean squared error (RMSE)

$$
R M S E=\sqrt{\frac{1}{g} \sum_{t=1}^{g}\left(\mathcal{R}(t)-\mathcal{R}^{\prime}(t)\right)^{2}}
$$

where $g$ represents the number of thermal risk estimations performed during the testing year.

Both measurements represent the average prediction error in the same units as the variable analysed and are negative oriented, thus, the lower values obtained represent more accurate estimation results. MAE is affected in direct proportion by the absolute value of the error while, RMSE gives more weight to large but infrequent errors. Thus, calculating both measures gives an idea of the overall performance of the estimation.

\section{B. Online Thermal Risk Estimation and Curtailment}

The online simulation considers the same data used in the offline simulation, however, it automatically performs curtailment of power generation when the methodology estimates a likely thermal risk $6 \mathrm{~h}$ ahead (black + blue steps in Fig. 1). For instance, if any percentage of risk is estimated at time $t$ a reduction in $I(t+1)$ is applied. The reduction in current is equivalent to the curtailment of the additional capacity installed according to the WFO case studied, in other words, the BWF rating $I_{B}(t+1)$ is applied. On the other hand, if no thermal risk is estimated the original input current $I(t+1)$ for the WFO case is used.

The modified input current profile $I_{\text {new }}(t)$ and corresponding conductor temperature $\mathcal{T}_{c_{\text {new }}}(t)$ are then used to calculate the next $6 \mathrm{~h}$ ahead thermal risk estimation $\mathcal{R}_{\text {new }}^{\prime}(t)$. Given that the original data profiles are modified in real time a new thermal risk $\mathcal{R}_{\text {new }}$ is calculated, while the risk estimation for the uncurtailed case $(\mathcal{R})$ is also stored for comparison.

The accuracy of the methodology to mitigate thermal risk is evaluated comparing the realistic thermal risk $\mathcal{R}(t)$ which would be faced if no curtailment was applied and the new real thermal risk $\mathcal{R}_{\text {new }}(t)$ considering the curtailment performed online. The compared values of thermal risk are classified as: no risk (NR) when $\left(\mathcal{R}_{\text {new }}(t)=\mathcal{R}(t)\right)=0$; risk mitigated (RM) when $\mathcal{R}_{\text {new }}(t)=0$ and $\mathcal{R}(t)>0$; risk decreased (RD) when $\mathcal{R}_{\text {new }}(t)<\mathcal{R}(t)$; risk increased (RI) when $\mathcal{R}_{\text {new }}(t)>$ $\mathcal{R}(t)$; and risk remained (RR) when $\left(\mathcal{R}_{\text {new }}(t)=\mathcal{R}(t)\right)>0$.

\section{RESUlts}

The results in this section correspond to the offline and online evaluation of the proposed methodology considering MCM of 1st and 3rd order TPM's using 4, 8 and 17 states, abbreviated as: $4 S \_\mathrm{MC} 1,4 S \_\mathrm{MC} 3,8 S_{-} \mathrm{MC} 1,8 S \_\mathrm{MC} 3$, $17 S \_\mathrm{MC} 1,17 S \_\mathrm{MC} 3$ through the rest of the section. DS1 was used for the modelling and evaluation of all the MCM in section V-A and V-B while DS2 is used in section V-C.

\section{A. Offline Simulation Results: DS1}

1) MAE and RMSE errors of thermal risk estimation: Fig. 4 summarises results corresponding to the one-year evaluation of MAE and RMSE errors between $\mathcal{R}^{\prime}$ and $\mathcal{R}$. As shown by the results the increment in the number of defined states did not improve the accuracy of the estimation as expected but generates slightly greater MAE and RMSE errors. On the other hand, the MC3 models generated better results for all the cases compared to the MC1 models. The most accurate predictions of thermal risk $6 \mathrm{~h}$ ahead are given by the $4 S \_$MC 3 model with a MAE $=0.0158$ and RMSE $=0.1057$ for WFO1, MAE $=0.0417$, and RMSE $=0.1728$ for $\mathrm{WFO} 2$ and, $\mathrm{MAE}=0.0419$ and RMSE $=0.1601$ for $\mathrm{WFO}$.

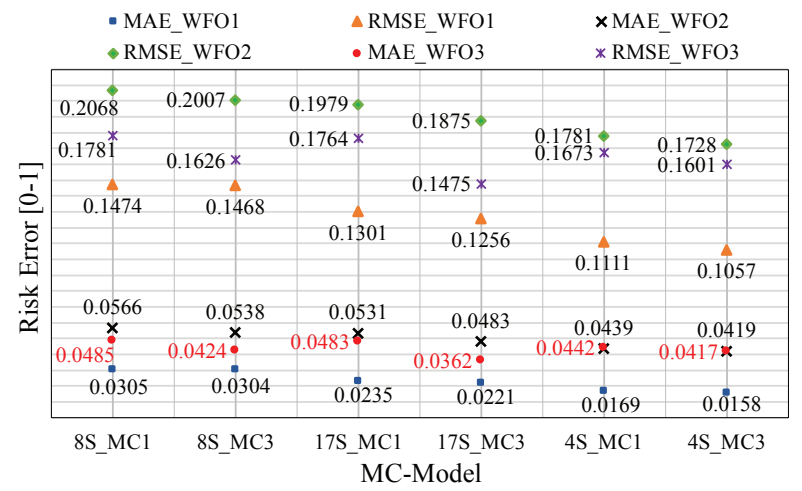

Fig. 4. Risk error calculated for the $6 \mathrm{MCM}$ and $3 \mathrm{WFO}$ cases.

2) Accuracy of risk estimation: Fig. 5 and Fig. 6 shown the results of the analysis of thermal risk using the classification in Table I. Each figure contains the results of the $6 \mathrm{~h}$ ahead estimation given by the models during the testing year for the overplanting cases WFO1 (Fig. 5) and WFO3 (Fig. 6).

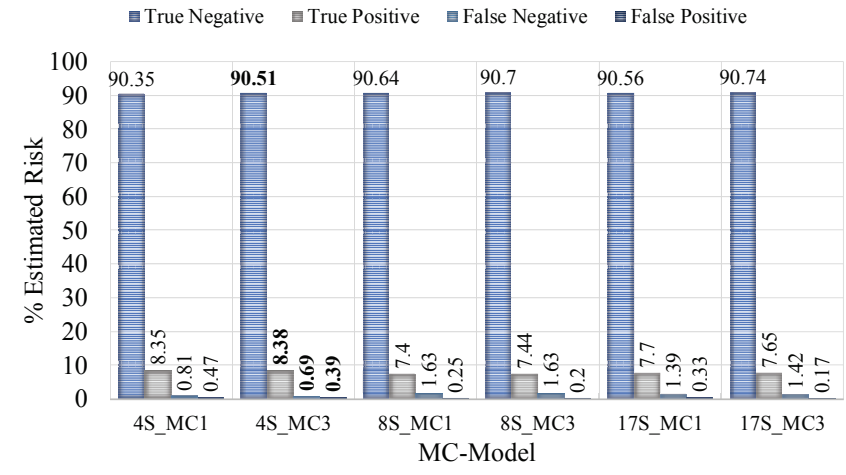

Fig. 5. Percentage of positive and negative estimations, WFO1.

The sum of percentages of $\mathrm{TP}+\mathrm{TN}$ represents successful estimations while $\mathrm{FN}+\mathrm{FP}$ represents unsuccessful estimations. Consistent with previous results, higher accuracy is obtained with $4 S \_\mathrm{MC} 3$ model for the $3 \mathrm{WFO}$ cases. The most accurate case is chosen as the one containing the highest percentage of positive identifications and the smallest percentage of FN as this case is potentially dangerous for the cable.

For the case of WFO1, in Fig. 5, 98.90\% of the thermal risk estimations correctly identified a thermal risk $6 \mathrm{~h}$ ahead while $1.10 \%$ were wrongly identified. As the overplanting and load current increases, the chances of exceeding the temperature 


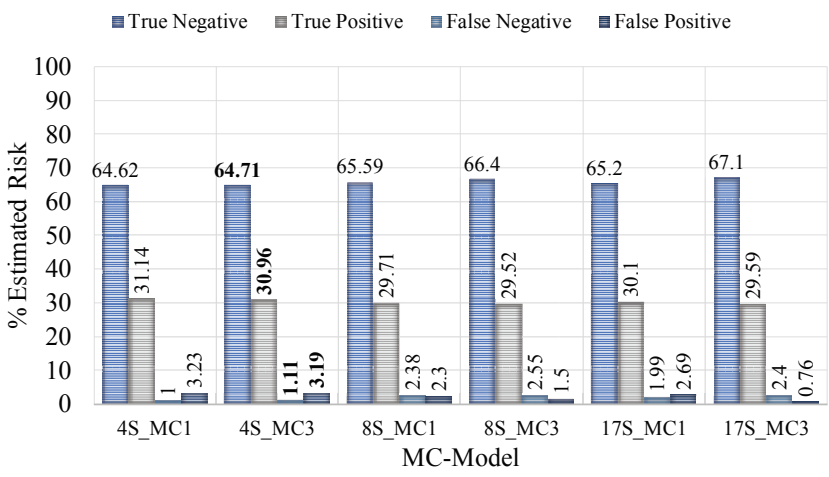

Fig. 6. Percentage of positive and negative estimations, WFO3.

limit also increase as seen for the WFO3 in Fig. 6 where the percentages of positive and negative estimations were $95.68 \%$ and $4.32 \%$ respectively.

3) MAE and RMSE temperature errors: The results of the temperature errors between $\mathcal{T}_{c 50}^{\prime}$ and $\mathcal{T}_{c}(t+6)$ are shown in Fig. 7. The $4 S \_M C 3$ model generated the smallest MAE and RMSE errors with a MAE $=4.6$ and $\mathrm{RMSE}=7.9$ for WFO1, $\mathrm{MAE}=5.1$ and $\mathrm{RMSE}=8.6$ for $\mathrm{WFO} 2$ and, $\mathrm{MAE}=5.5$ and $\mathrm{RMSE}=9.3$ for WFO3.

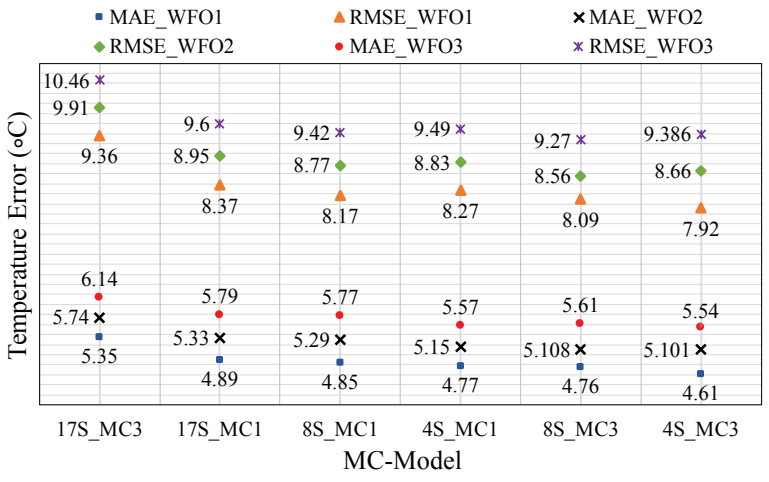

Fig. 7. Conductor temperature error calculated for the $6 \mathrm{MCM}$ and $3 \mathrm{WFO}$ cases.

A closer analysis of conductor temperature errors, considering $4 S \_$MC3 model, is presented in Fig. 8 for WFO1 case. The histogram of temperature errors obtained as: $\epsilon=$ $\mathcal{T}_{c}(t+6)-\mathcal{T}_{c_{50}}^{\prime}(t)$; is shown in Fig. 8-a while Fig. 8-b presents the conductor temperatures that the cable experienced at times when these groups of errors were calculated. The analysis shows that the chosen temperature $\mathcal{T}_{c_{50}}^{\prime}(t)$ as a point estimate represents a high to medium overestimation(-) or underestimation(+) during the periods of transitions from high to low or low to high load current states while it is accurate when high or low current loads are present in the cable. A ramp rate study and a sensitivity analysis at turning points could generate a more accurate point estimate for the purpose of accuracy in conductor temperature tracking.

Fig. 9-a shows the conductor temperature $\mathcal{T}_{c}$ for WFO1 compared to the estimated value $\mathcal{T}_{c_{50}}^{\prime}$ while, Fig. 9-b shows $\mathcal{T}_{c}$ along $\mathcal{T}_{c^{5}}^{\prime}$ and $\mathcal{T}_{c^{95}}^{\prime}$ which are the values correspond to the 5 th and 95th percentiles obtained from the obtained $\mathrm{PDF}_{\mathcal{T}_{c}^{\prime}}$. The values $\mathcal{T}_{c_{50}}^{\prime}(t), \mathcal{T}_{c^{5}}^{\prime}(t)$ and $\mathcal{T}_{c^{95}}^{\prime}(t)$ estimated at time $(\mathrm{t})$,
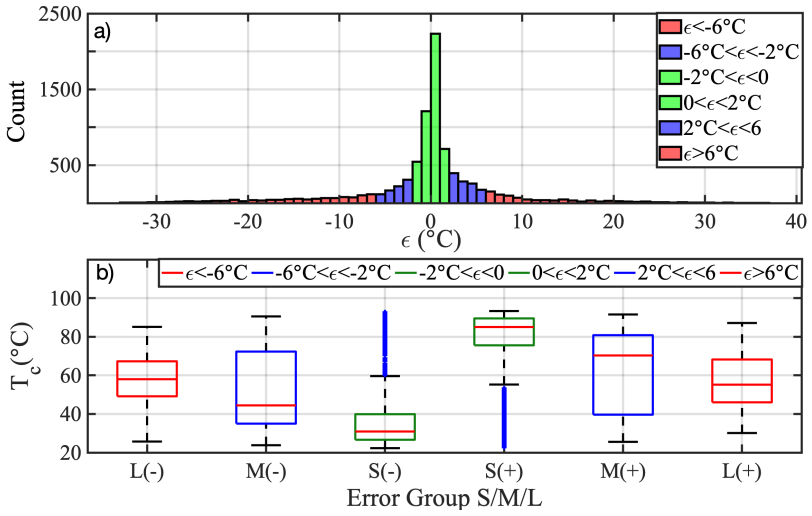

Fig. 8. Temperature error analysis 4 S_MC3, WFO1.

are depicted at time $(\mathrm{t}+6)$ to show the method's ability to estimate future load and conductor temperature based on the actual conductor temperatures and the cable thermal dynamics.

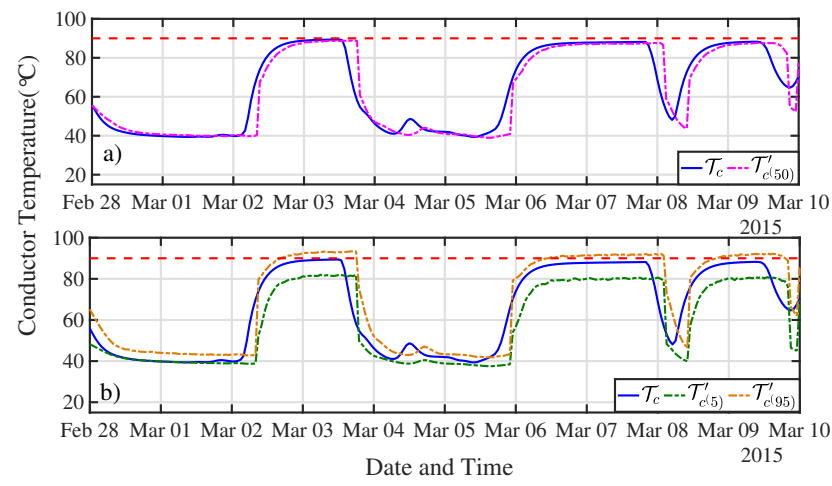

Fig. 9. Conductor temperature profiles, $4 S \_\mathrm{MC} 3$ model considering WFO1.

\section{B. Online Simulation Results with Curtailment, DSI}

The results from the simulated thermal risk estimation and curtailment are presented in Table II. The percentage of cases where the curtailment action mitigates the thermal risk $6 \mathrm{~h}$ ahead (RM) and no risk (NR) are summarised as Risk Mitigated while the cases where the thermal risk was increased, decreased or remained the same $(\mathrm{RI}+\mathrm{RD}+\mathrm{RR})$ are presented as Risk Remained. The grey rows in the table correspond to $4 S \_$MC3 model which generate the best risk mitigation percentages for the 3 WFO cases studied.

The severity of conductor temperatures for the Risk Remained percentages is evaluated in Fig. 10. The box plots in the figure are drawn by the values of conductor temperatures that still exceed the limiting temperature of the cable for each MC model and WFO case. The results evidence that, excluding the outliers, the remaining risk after curtailment results in temperatures which do not exceed $91.5^{\circ} \mathrm{C}$ even for the case of WFO3. Additionally, the mean temperature values for all the WFO cases and MCM are found below $90.5^{\circ} \mathrm{C}$ which could be compared to errors generated by DTS measurements that are within $\pm 1^{\circ} \mathrm{C}$ [30], [31].

Fig. 11-a presents the conductor temperature profile $\mathcal{T}_{c}$ for the case of WFO3 (4S_MC3) along the incidents (represented 
TABLE II

After Online Curtailment Evaluation

\begin{tabular}{|c|c|c|c|}
\hline WFO Case & MCM & Risk Mitigated & Risk Remained \\
\hline \multirow{6}{*}{ WFO1 } & 4S_MC1 & $98.37 \%$ & $1.62 \%$ \\
\hline & 4S_MC3 & $98.42 \%$ & $1.55 \%$ \\
\hline & 8S_MC1 & $94.49 \%$ & $5.50 \%$ \\
\hline & 8S_MC3 & $94.45 \%$ & $5.51 \%$ \\
\hline & 17S_MC1 & $95.13 \%$ & $4.86 \%$ \\
\hline & 17S_MC3 & $94.87 \%$ & $5.10 \%$ \\
\hline \multirow{6}{*}{ WFO2 } & 4S_MC1 & $95.89 \%$ & $4.10 \%$ \\
\hline & 4S_MC3 & $96.04 \%$ & $3.92 \%$ \\
\hline & 8S_MC1 & $92.51 \%$ & $7.48 \%$ \\
\hline & 8S_MC3 & $92.52 \%$ & $7.44 \%$ \\
\hline & 17S_MC1 & $93.43 \%$ & $6.56 \%$ \\
\hline & 17S_MC3 & $93.46 \%$ & $6.51 \%$ \\
\hline \multirow{6}{*}{ WFO3 } & 4S_MC1 & $97.96 \%$ & $2.03 \%$ \\
\hline & 4S_MC3 & $98.24 \%$ & $1.73 \%$ \\
\hline & 8S_MC1 & $92.33 \%$ & $7.66 \%$ \\
\hline & 8S_MC3 & $92.03 \%$ & $7.93 \%$ \\
\hline & 17S_MC1 & $94.75 \%$ & $5.24 \%$ \\
\hline & 17S_MC3 & $94.29 \%$ & $5.67 \%$ \\
\hline
\end{tabular}

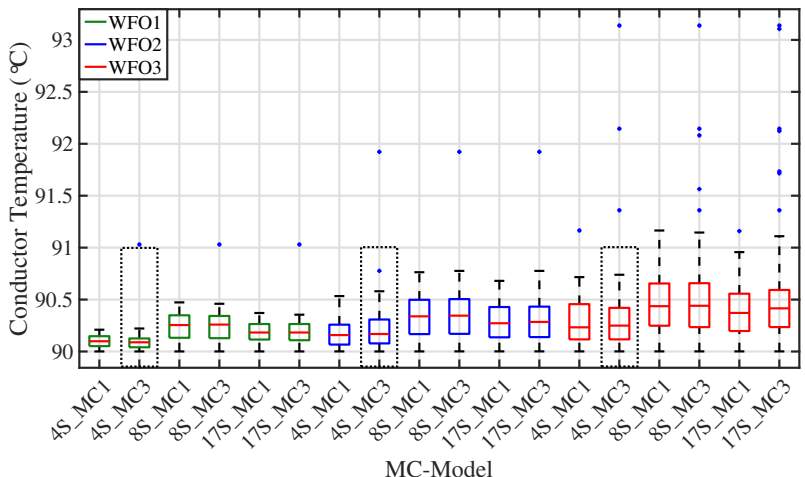

Fig. 10. Analysis of conductor temperature for the remaining thermal risk in Table II.

by $*$ in black) where the offline methodology estimates a forward temperature excedance $\left(\mathcal{R}^{\prime}\right)$ while Fig. 11-b shows the temperature profile $\mathcal{T}_{c_{\text {new }}}$ obtained considering the online estimation and curtailment. Fig. 11-b shows that if action is performed when the offline methodology estimates a forward risk $\mathcal{R}^{\prime}$ the risk of exceeding the $\mathcal{T}_{\text {limit }}$ is mitigated in $98.24 \%$ of cases while the remaining risk does not exceed $91^{\circ} \mathrm{C}$ as shown in Fig. 10.

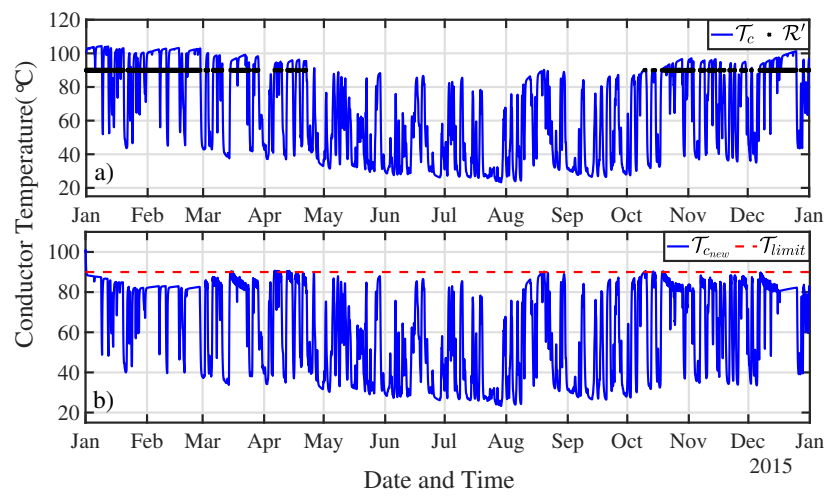

Fig. 11. Conductor temperature profile offline vs online calculation for WFO3, $4 S \_\mathrm{MC} 3$.
The approximate amount of additional power that could be transferred by the cables was derived from the online simulation as the difference between the base case power $P_{B}$ and the new profile of power $P_{\text {new }}$ calculated considering online curtailment during the year of testing. The resulting additional energy values are given in Table III accompanied by an approximate revenue calculated considering a cable length of $50 \mathrm{~km}$, a capital cost of $£ 1.2 \mathrm{~m}$ per $\mathrm{km}$, and an energy price of $£ 72.50 / M W h$ [32]. These results are accompanied by the percentage of remaining thermal risk presented above in Table II for the corresponding case studied.

TABLE III

Potential Benefits in Power Delivery

\begin{tabular}{|c|c|c|c|}
\hline WFO Case & MCM & $\begin{array}{c}\text { Additional } \\
G W h / \text { year }\end{array}$ & $\begin{array}{c}\text { Approx. Revenue } \\
\text { million } £ / \text { year }\end{array}$ \\
\hline \multirow{5}{*}{ WFO1 } & 4S_MC1 & 83.52 & 6.05 \\
& 4S_MC3 & 83.52 & 6.05 \\
\cline { 2 - 4 } & 8S_MC1 & 85.44 & 6.19 \\
\cline { 2 - 4 } & 8S_MC3 & 85.40 & 6.19 \\
\cline { 2 - 4 } & 17S_MC1 & 84.83 & 6.15 \\
\cline { 2 - 4 } & 17S_MC3 & 84.79 & 6.14 \\
\hline \multirow{5}{*}{ WFO2 } & 4S_MC1 & 105.19 & 7.62 \\
& 4S_MC3 & 105.34 & 7.63 \\
\cline { 2 - 4 } & 8S_MC1 & 110.53 & 8.01 \\
\cline { 2 - 4 } & 8S_MC3 & 110.92 & 8.04 \\
\cline { 2 - 4 } & 17S_MC1 & 109.36 & 7.92 \\
\cline { 2 - 4 } & 17S_MC3 & 109.72 & 7.95 \\
\hline \multirow{5}{*}{ WFO3 } & 4S_MC1 & 111.37 & 8.07 \\
\cline { 2 - 4 } & 4S_MC3 & 111.25 & 8.06 \\
\cline { 2 - 4 } & 8S_MC1 & 120.89 & 8.76 \\
\cline { 2 - 4 } & 8S_MC3 & 122.46 & 8.87 \\
\cline { 2 - 4 } & 17S_MC1 & 119.12 & 8.63 \\
\cline { 2 - 4 } & 17S_MC3 & 121.35 & 8.79 \\
\hline
\end{tabular}

\section{Offline and Online Simulation Results: DS2}

The results in this section were obtain considering DS2 and the $4 S \_$MC3 model for the 3 WFO cases.

1) Offline simulation results: The results of the MAE and RMSE for thermal risk and conductor temperature are both shown in Fig. 12 distinguished by the subindex $R$ and $T$. The calculated MAE_ $R$ lie between 0.0061 and 0.0277 while RMSE_ $R$ lie between 0.068 and 0.1367 for the corresponding cases of WFO1 and WFO3. For the case of MAE_T the maximum and minimum error values were between $4.793^{\circ} \mathrm{C}$ and $5.547^{\circ} \mathrm{C}$ while RMSE_ $T$ values were between $7.795^{\circ} \mathrm{C}$ and $8.891^{\circ} \mathrm{C}$ for $\mathrm{WFO} 1$ and $\mathrm{WFO} 3$ respectively.

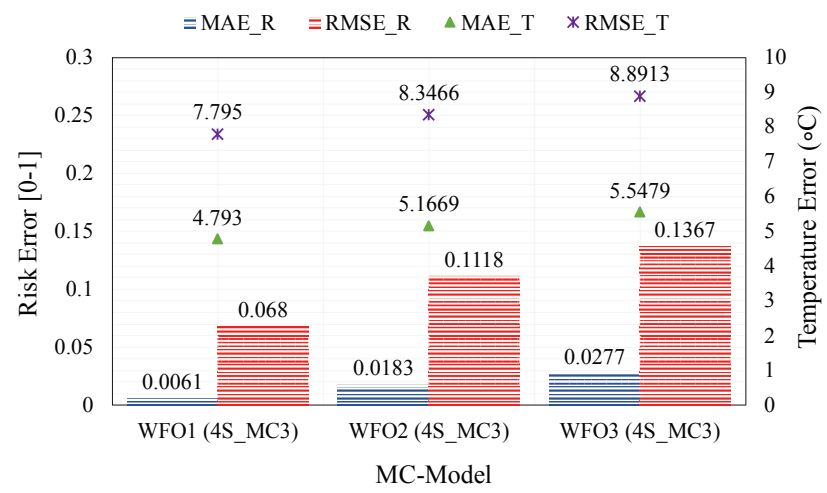

Fig. 12. MAE and RMSE errors of thermal risk and conductor temperature. 
These results compared to results obtained using DS1 generate lower values of error related only to the historical data set from the studied offshore location. For instance, it was noticed that the profile of wind speed during the winter months at the beginning and end of the testing year in DS2 was not as strong as in DS1 which in this case generate shorter periods of maximum load current generation and consequently lower chances of conductor temperature exceedances in the three overload cases.

The lower percentage of temperature exceedances in DS2 is also evident in the positive and negative percentages of thermal risk accuracy presented in Fig. 13, where WFO1 presented a $98.54 \%$ of TN risk and just a $0.89 \%$ of TP risk during the testing year while $\mathrm{FN}+\mathrm{FP}$ represented a $0.56 \%$ of the estimations. In the case of WFO3 the percentage of $\mathrm{TN}$ was $80.55 \%$ TP was $17.39 \%$ and $\mathrm{FN}+\mathrm{FP}$ was $2.06 \%$ which is less than half the negative cases compared to DS1 in Fig. 6.

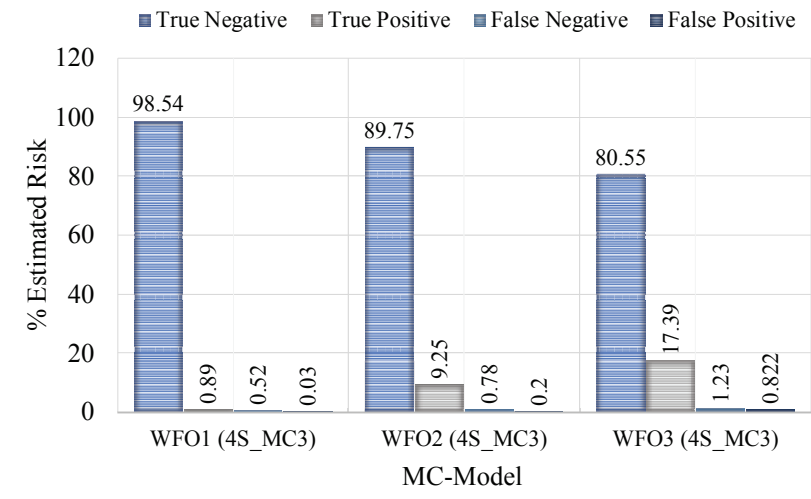

Fig. 13. Percentage of positive and negative thermal risk estimations.

2) Online simulation results: The evaluation of thermal risk after curtailment for DS2 show a small percentage of remaining risk, between $1.11 \%$ and $2.09 \%$, considering all the WFO cases as seen in Table IV. The economic analysis results are summarised in the same table, showing that the resulting additional power and approximate revenues were greater for WFO2 and WFO3 compared to the results from $4 S \_\mathrm{MC} 3$ in Table III due to the originally lower load current generated in offshore site.

TABLE IV

After Online Curtailment Evaluation \& Potential Economic BENEFITS

\begin{tabular}{|c|c|c|c|c|}
\hline \multicolumn{5}{|c|}{ 4S_MC3 Model } \\
\hline \multirow{2}{*}{$\begin{array}{c}\text { WFO } \\
\text { case }\end{array}$} & \multicolumn{2}{|c|}{ Risk } & \multicolumn{2}{c|}{ Economic Benefits } \\
\cline { 2 - 5 } & Mitigated & Remaining & $\begin{array}{c}\text { Additional } \\
G W h / \text { year }\end{array}$ & $\begin{array}{c}\text { Approx. Revenue } \\
\text { Million } £ / \text { year }\end{array}$ \\
\hline WFO1 & $98.88 \%$ & $1.11 \%$ & 78.27 & 5.67 \\
\hline WFO2 & $97.90 \%$ & $2.09 \%$ & 106.95 & 7.75 \\
\hline WFO3 & $98.20 \%$ & $1.79 \%$ & 122.62 & 8.89 \\
\hline
\end{tabular}

Finally, the severity analysis of conductor temperatures was within $91^{\circ} \mathrm{C}$ for the three overplanting cases, as per Fig. 14 .

\section{Discussion: EFFECTS OF ChARging CURRENT IN THE CABLE}

The submarine section of the cable used represents the middle section of the export system studied ( $25 \mathrm{~km}$ offshore),

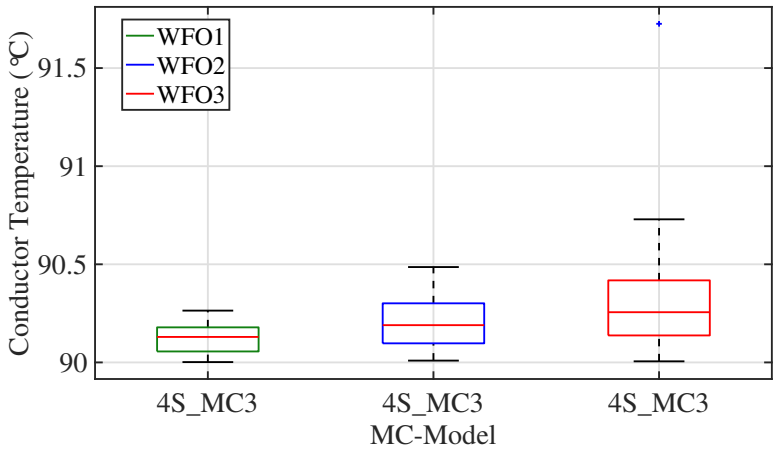

Fig. 14. Analysis of conductor temperature exceedances for remaining thermal risk in Table IV.

which would reflect almost no charging current impact considering reactive compensation at both ends of the cable route. The maximum reactive current at one end of the cable would be $5 \mathrm{~A} / \mathrm{km} \times 50 \mathrm{~km}=250 \mathrm{~A}$ in the worst case scenario thus, considering a full load continuous rating $I_{s}=923 \mathrm{~A}$ the reactive current would lead to an increased current $I_{c_{1}}=931 \mathrm{~A}$ $(\leq 1 \%)$ without compensation.

Charging current effects would vary according to the case studied depending on; the type of cable, operating voltage, cable length, location of the reactive compensation, and point of estimation in the transmission line (landfall, submarine sections, offshore end). Thus, depending on the particular case, charging current effects must be calculated and added to the load current profile data.

The addition of the charging current into the load current profile would limit the minimum value of load current that is possible to reach, thus, the calculated probabilities in the TPM's would change if the lower state(s) of the system become(s) less probable or physically impossible to attain. However, the thermal risk estimation methodology would not be affected given that the statistical analysis of the data performed by the MCM would automatically reflect the changes performed to the given set of data. Finally, the number of additional wind turbines that could be connected to the cable will be affected, thus, WFO cases (also induced in the data) must be adjusted according to the studied cable system.

\section{CONCLUSION}

A methodology was presented for the forward thermal risk estimation in WF export cables considering uncertainty in power generation. Future likely conductor temperatures in the system are estimated through the use of monthly TPM derived from 5 years of data MCS and a FDM of the cable. Six MCM with a different number of system states and higher order TPM's were developed and evaluated.

Overplanting cases induced the risk of the cable exceeding $90^{\circ} \mathrm{C}$ and the methodology proved to generate a high percentage of positive identifications of risk $6 \mathrm{~h}$ ahead from $95.68 \%$ in WFO3 to $98.09 \%$ in WFO1 during one year of offline testing with a MAE of 0.0158 and 0.0419 respectively. An online application of the methodology including a simulated curtailment strategy generated a high percentage of thermal risk mitigation while analysis the remaining percentage of 
thermal exceedances did not exceed a temperature higher than $91.5^{\circ} \mathrm{C}$ for DS1 and $91^{\circ} \mathrm{C}$ for DS2.

Additional power delivery of $7.26 \%, 9.16 \%$ and $9.67 \%$ per year was enabled compared to the traditional limiting rating based on IEC60287 (1149.58 GWh/year) with a calculated approximate revenue of $6.05,7.63$ and 8.06 million $£$ /year for DS1. Tests performed in two datasets from different offshore locations proved that the statistically-based method is easy to use, non-restrictive or parametric to a specific set of data.

\section{REFERENCES}

[1] I. E. C. (IEC), "International Standard IEC 60287-1-1; Electric cables-Calculation of the current rating-Part 1-1."

[2] J. K. Dix, T. J. Hughes, C. J. Emeana, J. A. Pilgrim, T. J. Henstock, T. M. Gernon, and C. E. L. Thompson, "Substrate controls on the lifetime performance of marine HV cables," in Smarter Solutions for Future Off shore Developments, 2017, pp. 88-107.

[3] G. J. Anders and H. Brakelmann, "Rating of Underground Power Cables With Boundary Temperature Restrictions," IEEE Transactions on Power Delivery, vol. 33, no. 4, pp. 1895-1902, 2018.

[4] J. A. Pilgrim and S. Kelly, "Thermal and economic optimisation of windfarm export cable," in IET Renewable Power Generation 2018, Lyngby, Denmark, 2018, pp. 1-6.

[5] S. Catmull, R. Chippendale, J. Pilgrim, G. Hutton, and P. Cangy, "Cyclic Load Profiles for Offshore Wind Farm Cable Rating," IEEE Transactions on Power Delivery, vol. 8977, no. c, pp. 1-1, 2015.

[6] T. Kvarts, I. Arana, R. Olsen, and P. Montensen, "Systematic Description of Dynamic Load for Cables for Offshore Wind Farms . Method and Experience," 2016.

[7] C. Wolter, H. Klinge Jacobsen, G. Rogdakis, L. Zeni, and N. A. Cutululis, "Overplanting in offshore wind power plants in different regulatory regimes," in 15th Workshop on Integration of Wind Power into Power Systems, 2016.

[8] H. J. Li, K. C. Tan, and Q. Su, "Assessment of underground cable ratings based on distributed temperature sensing," IEEE Transactions on Power Delivery, vol. 21, no. 4, pp. 1763-1769, 2006.

[9] J. A. Pilgrim, S. Catmull, R. Chippendale, P. L. Lewin, and P. Stratford, "Current Rating Optimisation for Offshore Wind Farm Export Cables," in Cigre 2014, 2014, pp. 1-6.

[10] S. Cherukupalli, G. A. MacPhail, R. E. Nelson, J. S. Jue, and J. H. Gurney, "Application of Distributed Fibre Optic Temperature Sensing on BC Hydro's 525kV Submarine Cable System," in Cigre 2014, 2014, pp. 1-9.

[11] H. Brakelmann, H. Hirsch, A. Röhrich, H.-p. Scheiffarth, and J. Stammen, "Adaptive monitoring program for dynamic thermal rating," in Jicable 2007, 2007.

[12] S. P. Walldorf, S. John, and F. J. Hoppe, "The Use of Real-Time Monitoring and Dynamic Ratings for Power Delivery Systems and Implication for Dielectric Materials," IEEE Electrical Insulation Magazine, pp. 28 33, 1999.

[13] A. Michiorri, H. M. Nguyen, S. Alessandrini, J. B. Bremnes, S. Dierer, E. Ferrero, B. E. Nygaard, P. Pinson, N. Thomaidis, and S. Uski, "Forecasting for dynamic line rating," Renewable and Sustainable Energy Reviews, vol. 52, pp. 1713-1730, 2015.

[14] S. C. Jupe, D. Kadar, G. Murphy, M. G. Bartlett, and K. T. Jackson, "Application of a dynamic thermal rating system to a $132 \mathrm{kV}$ distribution network," in IEEE PES Innovative Smart Grid Technologies Conference Europe, 2011, pp. 1-8.

[15] D. J. Morrow, J. Fu, and S. M. Abdelkader, "Experimentally validated partial least squares model for dynamic line rating," IET Renewable Power Generation, vol. 8, no. 3, pp. 260-268, 2014.

[16] F. Pimenta, W. Kempton, and R. Garvine, "Combining meteorological stations and satellite data to evaluate the offshore wind power resource of Southeastern Brazil," Renewable Energy, vol. 33, no. 11, pp. 23752387, 2008.

[17] T. G. Barbounis, J. B. Theocharis, M. C. Alexiadis, and P. S. Dokopoulos, "Long-Term Wind Speed and Power Forecasting Using Local Recurrent Neural Network Models," IEEE Transactions on Energy Conversion, vol. 21, no. 1, pp. 273-284, 2006.

[18] T. El-Fouly, E. El-Saadany, and M. Salama, "One Day Ahead Prediction of Wind Speed and Direction," IEEE Transactions on Energy Conversion, vol. 23, no. 1, pp. 191-201, 2008.
[19] R. Karki, S. Member, P. Hu, S. Member, R. Billinton, and L. Fellow, "A Simplified Wind Power Generation Model for Reliability Evaluation," IEEE Trans. on Energy Conversion, vol. 21, no. 2, pp. 533-540, 2006.

[20] A. Carpinone, M. Giorgio, R. Langella, and A. Testa, "Markov chain modeling for very-short-term wind power forecasting," Electric Power Systems Research, vol. 122, pp. 152-158, 2015.

[21] A. M. Foley, P. G. Leahy, A. Marvuglia, and E. J. McKeogh, "Current methods and advances in forecasting of wind power generation," Renewable Energy, vol. 37, no. 1, pp. 1-8, 2012.

[22] J. Jung and R. P. Broadwater, "Current status and future advances for wind speed and power forecasting," Renewable and Sustainable Energy Reviews, vol. 31, pp. 762-777, 2014

[23] L. Exizidis, F. Vallée, Z. De Grève, J. Lobry, and V. Chatziathanasiou, "Thermal behavior of power cables in offshore wind sites considering wind speed uncertainty," Applied Thermal Engineering, vol. 91, pp. 471478, 2015.

[24] Y. Li and J. Niu, "Forecast of power generation for grid-connected photovoltaic system based on Markov chain," in Asia-Pacific Power and Energy Engineering Conference, 2009, pp. 9-12.

[25] G. Anders and G. Georgallis, "Transient analysis of 3-core SL-type submarine cables with jacket around each core," Jicable 2015, pp. 3-4, 2015.

[26] R. Huang, J. A. Pilgrim, P. L. Lewin, D. Scott, and D. Morrice, "Managing cable thermal stress through predictive ratings," in 33rd Electrical Insulation Conference (EIC 33), no. June, 2015, pp. 110-113.

[27] K. F. Goddard, J. A. Pilgrim, R. Chippendale, and P. L. Lewin, "Induced losses in three-core SL-type high-voltage cables," IEEE Transactions on Power Delivery, vol. 30, no. 3, pp. 1505-1513, 2015.

[28] M. M. Rienecker, M. J. Suarez, R. Gelaro, and R. Todling, "MERRA : NASA' s Modern-Era Retrospective Analysis for Research and Applications," Jounal of Climate, vol. 24, pp. 3624-3648, 2011.

[29] M. A. Hernandez Colin and J. A. Pilgrim, "Offshore Cable Optimization by Probabilistic Thermal Risk Estimation," 2018 IEEE International Conference on Probabilistic Methods Applied to Power Systems (PMAPS), pp. 1-6, 2018.

[30] A. Ukil, H. Braendle, and P. Krippner, "Distributed temperature sensing: Review of technology and applications," IEEE Sensors Journal, vol. 12, no. 5, pp. 885-892, 2012.

[31] J. Downes and S. Sensa, "Distributed Temperature Sensing Worldwide Power Circuit Monitoring Applications," Power system Technology, 2004, PowerCon 2004., vol. 2, no. November, pp. 1804-1809, 2004.

[32] Dep. for Business Energy \& Industrial Strategy, "CfD Results 2017." [Online]. Available: www.gov.uk/government/collections/contracts-fordifference-cfd-second-allocation-round

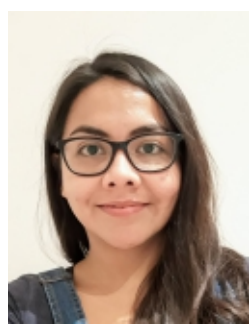

Maria Angelica Hernandez Colin: Received a BEng. in Electronic Engineering in 2011 and a MEng. in Electrical Engineering in 2015 from the Institute of Technology of Madero City, Mexico. She is currently pursuing a $\mathrm{PhD}$ in the Electrical Power Engineering (EPE) group at the University of Southampton.

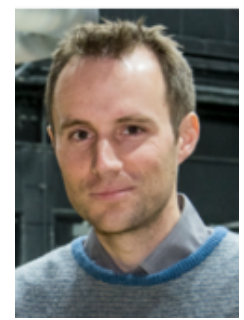

James A. Pilgrim (M'09, SM'17): Received the Bachelor's degree in electrical engineering from the School of Electronics and Computer Science at the University of Southampton in 2007. He joined the staff of the University of Southampton in 2007 as a Research Assistant, gaining his $\mathrm{PhD}$ in 2011. He joined the academic staff of the University in 2012. His research interests include all aspects of high voltage cables and associated insulation systems. $\mathrm{He}$ is currently the Chair of the DEIS Technical Committee on Smart Grid. He is actively involved in the development of current rating methodologies, acting as the UK member of IEC TC 20 WG19 (Current Rating and Short Circuit Limits of Cables) and Cigre Working Groups B1.35 "Guide to rating calculations", B1.56 "Current rating verification" and B1.64 "Evaluation of losses in armoured three core cables". 